\title{
THE EXPLORATION OF APPLYING OF SPATIAL INFORMATION TECHNOLOGY IN GENERAL PLAN FOR REGIONAL CULTURAL HERITAGE CONSERVATION
}

\author{
Yecheng Liu, Yuchen Zhuang \\ Studio Two, Beijing Guowenyan Cultural Heritage Preservation Center, Beijing, China-286529273@qq.com
}

KEY WORDS: Regional Cultural Heritage Preservation, Photogrammetry Modeling, Geographic Information System, 3D Laser Scanning

\begin{abstract}
:
With the rapid urbanization and the sharp increasing of the amount of official identification cultural heritages, the Chinese government and public are paying more attention to the regional comprehensive preservation, exhibition and utilization of the cultural heritages in recent years. "General Plan for Regional Cultural Heritage Preservation" offers a new systematic conservating solution for the cluster of cultural heritages in an administrative region. For the past few years, lots of new spatial information technologies have been applied in the preservation of cultural heritages, which tremendously improved the level and effectiveness of cultural heritage recording, management, monitoring and exhibition. This article will focus on discussing the methods and applying prospect of the technologies of geographic information system, 3D laser scanning, photogrammetry modeling in general planning for regional cultural heritage preservation and utilization.
\end{abstract}

In recent years, with the continuous development of cultural heritage preservation in China, an increasing number of provinces and cities began to organize General Plans for regional cultural heritage preservation (hereinafter called "General Plan"), through which local governments are able to control the risk and improve the preservation level of cultural heritage. (IAH, 2004) This paper will introduce the working framework of the General Plan and the core problems to be solved, and then analyze the application mode and prospect of spatial information technology in the General Plan.

\section{THE GENERAL PLAN AND THE SPATIAL INFORMATION TECHNOLOGY}

\subsection{The Working Object of General Plans}

The cultural heritage preservation units (hereinafter called "Preservation Units"), are the preservation titles and organizations for immovable relics, which identified by the governments at various levels in mainland China. According to the Law of the People's Republic of China, governments at all levels should compile the conservation plans for each Preservation Unit to guide the conservation work. Different from the conservation plan of one single Preservation Unit, General Plans takes the cluster composed by all Preservation Units of a certain administrative region as the planning object. (Shi, 2013)

\subsection{The Work Contents of General Plans}

1. Multi-disciplinary thematic studies and cultural heritage value researches, which provide the basis for subsequent cultural heritage status assessment and planning.

2. Comprehensive and systematic assessments on the current preservation and management situation, disease causes and risk levels of the Preservation Units.

3. Suggestions on the construction of preservation element system and the adjustment plan of the protection zoning for the Preservation Units.

4. Formulating optimization proposals for the process of inspection management, monitoring and supervision, project application, project approval, evaluation, implementation and acceptance inspection in the protection of regional Preservation Units, so as to improve the 
utilization efficiency of funds and manpower in the local cultural heritages management system. (Shi, 2013)

5. Evaluation of the display and utilization potential of each Preservation Units quantitatively which provides support for the spatial system planning of regional Preservation Units display and utilization.

6. Formulating a database of key projects for the protection and utilization of regional Preservation Units, such as laws and planning system formulating, cultural heritage investigation, archaeology and research work, preservation and display projects, environmental renovation projects, and digital recording work.

\subsection{Application of Spatial Information Technology in General Plans}

Space information technology is a scientific and technological field in which space technology, remote sensing technology, computer application, geographic information system, multimedia and virtual technology are used to obtain, process, analyze, store and transmit geospatial information with clear spatial scale and positioning meaning. Since the 1990s, spatial information technology has been widely used in the field of cultural heritage preservation. (Mao, 2008)

With the characteristics of "large space scope" and "large number of working objects", General Plans has higher requirements for the collection, analysis, management and inquiry of cultural heritages' spatial data in the process of planning compilation and later implementation. At the same time, remote sensing data and spatial model data are also widely used in the process of digital recording, dynamic monitoring and management of cultural heritages. How to make use of limited human resources and funds to efficiently apply spatial information technology into cultural heritage preservation plan is a long-term research topic. According to the author's practical experience in a number of General Plans, spatial information technology can provide strong support for planning and implementation in the following three aspects:

1. Collection, storage, analysis, query and quick drawing of geographical information and preservation data. (Mao, 2008)
2. The collection and production of $3 \mathrm{D}$ model data of Preservation Units in large quantities and at low cost provides basic data conditions for the protection and display and utilization of cultural heritages.

3. By comparing the $3 \mathrm{D}$ point cloud model of different times, the disease of Preservation Units can be accurately located.

This paper expounds the application of GIS, 3D laser scanning and UAV photogrammetry technologies in General Plans from the above three perspectives.

\section{THE APPLICATION OF GEOGRAPHIC INFORMATION SYSTEM IN GENERAL PLANS.}

\subsection{Field Investigation Planning}

Prior to the field investigation of General Plans, the geographical information database needs to be built and the relevant Preservation Units information data extracted from the archives and historical documents are input into the database, and the investigation plan and route can be reasonably formulated according to the spatial information from the database.

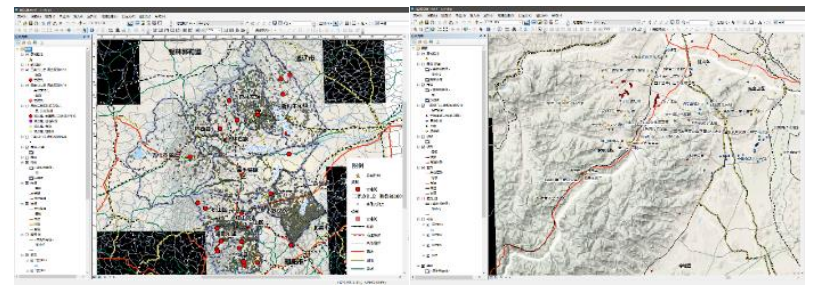

Figure 1. Making investigation plans by GIS

\subsection{Data Analysis and Decision-Making Assistant}

In the process of field investigation and planning, topographic mapping, Preservation Units assessment results and planning measures will be incorporated into the geographic information database platform, and comprehensive cross-analysis of data and spatial interpolation analysis will be carried out to improve the efficiency and rationality of planning compilation. 

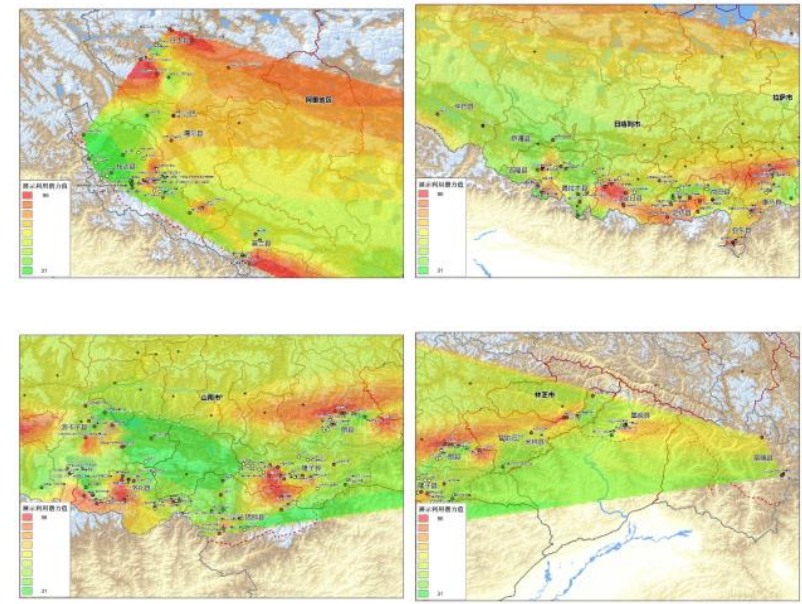

Figure 2. Natural neighbor interpolation analysis of utilization potential of Preservation Units

\subsection{Cultural Heritage Preservation and Management Information Platform}

The information platform of cultural heritage preservation and management (hereinafter called "Platform"), which bases on GIS technology, is constructed by using the various cultural heritage preservation data in the geodatabase, is produced during the compilation of General Plans. The platform consists of three modules: the server side, the web side and the mobile terminal, supports 2D map, 3D model, satellite image data, vector data and other spatial data formats. The Platform realizes the basic functions such as regional management of Preservation Units, real-time data query and geo-spatial labeling. it also expands the following four practical functions to improve the efficiency and level of regional Preservation Units management.

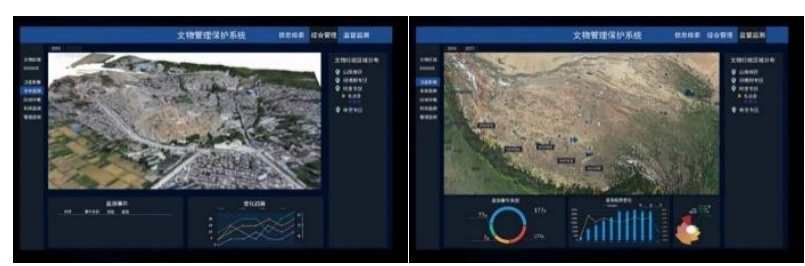

Figure 3. Cultural heritage preservation and management information platform of Tibet Autonomous Region

\section{Thematic Map Generation}

By loading the data of preservation status, protection zoning and planning control requirements of Preservation Units, which are stored in the geodatabase, the Platform outputs thematic maps into CAD and JPG files, in which the components such as legend, wind rose and scale are generated automatically.

\section{Integrated Management}

Based on the spatial and information-based characteristics, the Platform is able to help the administrative departments of cultural heritages preservation at various levels to realize the online managements of project approval and fund application. The functions of project progress tracking, planning conditions inquiry and relics related construction project approval, which are provided by the Platform, improve the implementation of General Plans significantly.

\section{Dynamic Monitoring}

The function module is able to provide assistant for the grassroots inspectors and administrators through a simple and easy-to-use operation interface by IPAD terminal. Administrative departments can make use of various kinds of data, including pictures, video and satellite remote sensing data, which are stored in the geodatabase, to carry out multi-period data comparison and timely locate problems in the protection of Preservation Units.

\section{Public Participation}

This function can be used to release the basic information of Preservation Units and the information of the heritage related plan to the public, so that the public can fully understand the cultural connotation of cultural heritages, protection status, planning compilation and specific project approval, and collect public opinions on the protection of cultural heritages at the same time.

\section{Cultural Heritage Preservation and Management Information Platform}

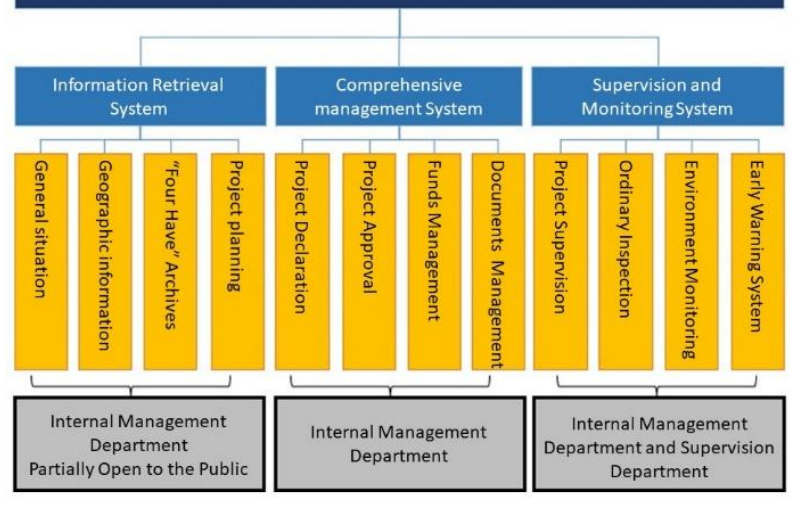

Figure 4. the Framework of the cultural heritage preservation and management information platform 


\section{APPLICATION OF UAV PHOTOGRAPHY MODELING IN GENERAL PLANS}

\subsection{Technical Process}

\subsubsection{Preparatory Work}

In the practice of UAV photogrammetry, DJI MAVIC 2 professional UAV is selected as the data acquisition equipment for its most comprehensive performance. The UAV has three major advantages: good lens imaging quality, good flight performance, light and portable.(Yu, 2019)

In the process of Investigation, the General Plan team chose Pix4dCapture as a third-party flight planning App, mainly because of its convenient aerial survey planning function: Pix4dCapture has five flight modes, by which users can easily set the flight area, altitude, image overlap rate and camera angle. (Song, 2019)

In the filed investigation of General Plans, the time for each Preservation Unit is limited and the investigation task is heavy. In order to save time, the General Plan team usually completes the flight path planning in advance. The location of the Preservation Units can be found in Pix4dCapture, the flight route mode can be selected according to the type of Preservation Units, and the aerial survey area can be arranged according to the actual needs, and the flight altitude can be determined according to the required GSD value, and saved in the task list of the App.

\subsubsection{Data Collection}

In the investigation process, the planning team mainly use the double grid flight mode and the circular flight mode of Pix4dCapture software, combined with the DJI GO software to manually control the UAV to get necessary supplement data:

1. For large scale and flat distribution Preservation Units, such as city sites and building groups, the double grid flight mode provided by Pix4dCapture should be a good choice for data collection. This mode ensures that images are taken from multiple sides, with overlapping areas required for 3D modeling. During the acquisition process, it is advisable to fly as close to the subject as possible to capture more vertical details.

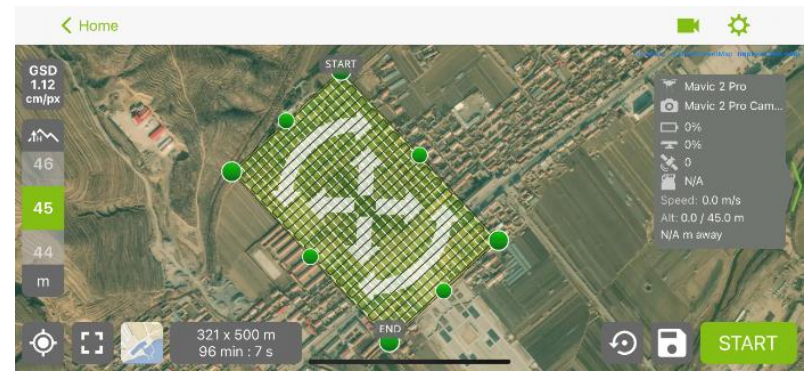

Figure 5. the Double grid flight mode

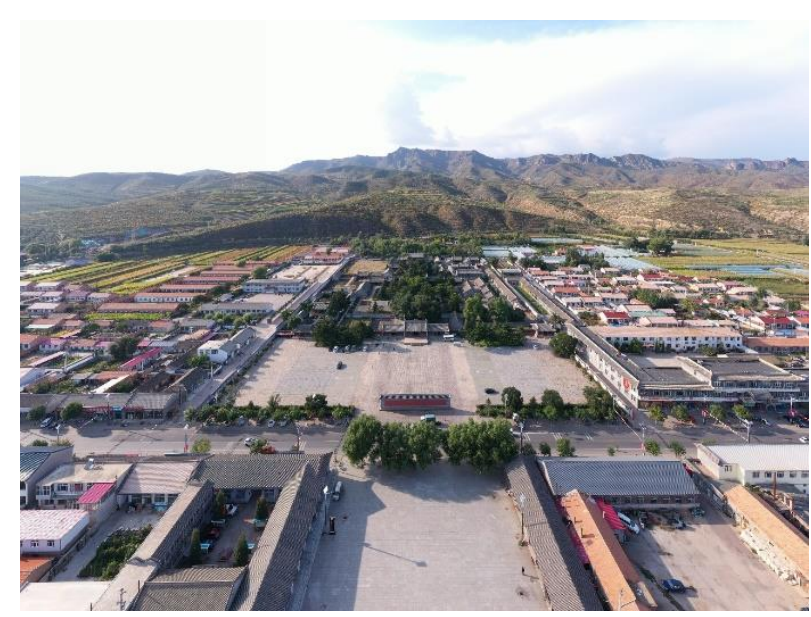

Figure 6. the King Harqin Banner Mansion

2. For the Preservation Units with relatively small and independent acquisition targets, such as gate towers and ancient pagodas, the circular flight mode should be a good choice for data collection. The mode ensures that the image is taken from all angles around the target and has sufficient overlapping areas needed for 3D modeling. In the process of data collection, it is advisable to shoot the cultural heritages in different heights by flying around for several times.

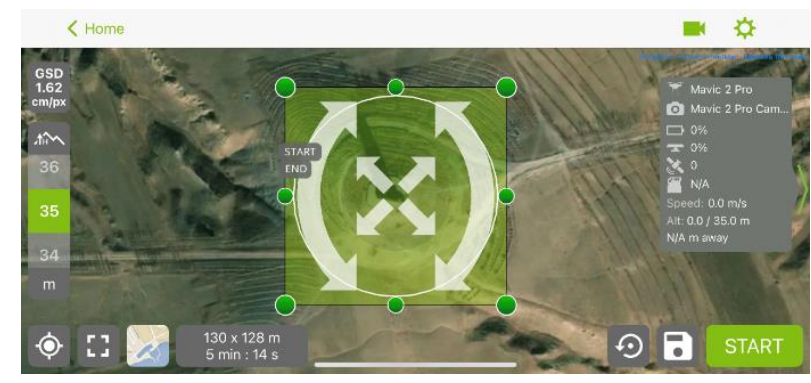

Figure 7. the Circular flight mode 


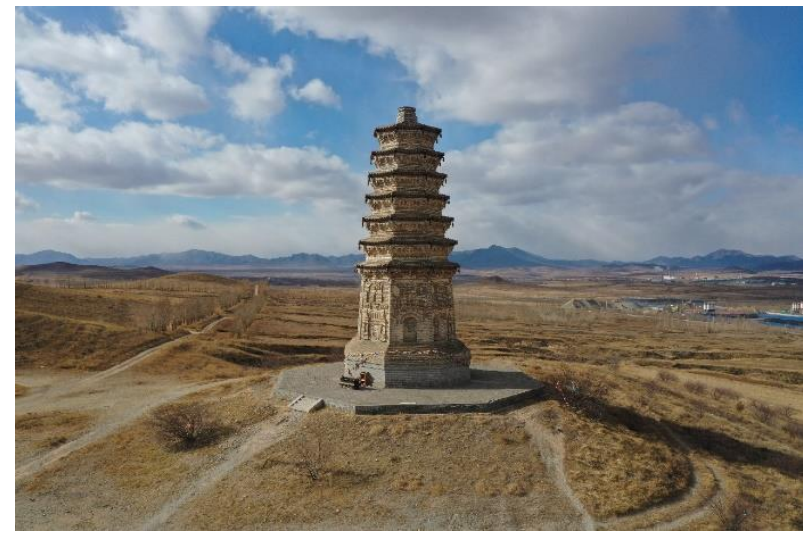

Figure 8. the South Tower of Liaoshangjing Site

3. In the process of data collection, due to the different layout, volume and shape of Preservation Units, aerial photography can be manually supplemented for key areas of cultural heritages or special angles, which are difficult to be captured by the aforementioned flight mode on the basis of the completion of the double grid flight mode or the circular flight mode, so as to obtain more detailed information on the site.

\subsubsection{Data Processing}

In the data processing stage, planning team choses Agisoft Metashape Professional as the data processing software. The software has big computing power, multiple functions, and is convenient and fast. Based on the photos taken by the UAV, it can generate 3D models of the Preservation Units, and present the modeling results in form of dense point cloud, OBJ, 3DS, WRL and other frequently-used 3D formats for further data processing.(Liu,2017)

\subsection{Applications}

\subsubsection{Archive}

The 3D models, which contain the conditions and environments of the Preservation Units, are saved and archived in the digital form. It is convenient to check whether the Preservation Units and the environmental conditions have been changed recently.

\subsubsection{Data Analysis and Applications}

By using Agisoft Metashape Professional, the planning team can analyze and apply the 3D model data of the Preservation Units in a variety of ways, including:

1. Generate Orthophoto
Orthophoto of the plane and elevation can be generated from the 3D model data of the Preservation Units directly, which can be used to understand the surface contour and topography and other conditions of Preservation Units.

\section{Classification of Dense Point Cloud}

The dense point cloud can be classified as buildings, roads, plants, roads and other categories to realize the preliminary analysis of the site environment of Preservation Units.

\section{Digital Elevation Model}

For relatively large model, digital elevation in DSM/DTM format can be generated according to the model, and then the software of ArcGIS can be used for further analysis of site elevation, slope, slope aspect, water catchment, line of sight, etc.

\section{Presentation Film}

Parameters such as camera position and camera motion track can be set according to needs for the generating of short films, which can be used for the cultural heritages and environmental scene display.
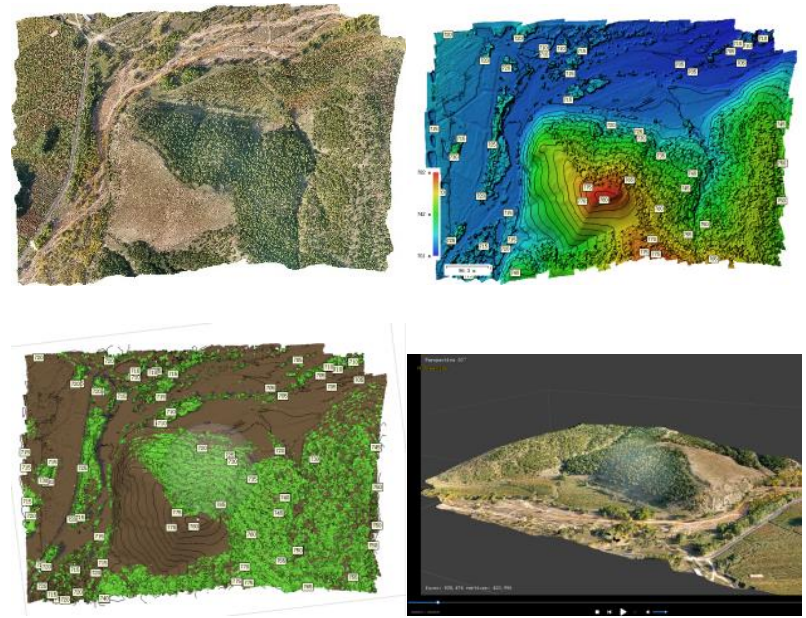

Figure 9. Orthophoto, Digital elevation model, Classification of dense point cloud, and Presentation film

\subsection{Efficiency and Cost}

In the practice of General Plans, the planning team found that UAV photogrammetry had the characteristics of high efficiency and low cost in terms of on-site data collection of a large number of Preservation Units. 
Take the 3D modeling project in "the general plan of Chifeng cultural heritages conservation" for example, the Planning team, which was divided into three groups, investigated 412 Preservation Units that spread over $90021 \mathrm{~km}^{2}$ in Chifeng of Inner Mongolia in 15 days, during which the three groups collected UAV photogrammetry data for over 100 Preservation Units.

As survey area and flight parameters can be set in advance and the UAV can fly to collect data and return automatically, Investigators are able to devote themselves to Preservation Units assessment and other work within limited time of on-site investigation.

\begin{tabular}{|l|c|c|c|}
\hline Investigation Group No. & 1 & 2 & 3 \\
\hline Number of investigators & 3 & 3 & 3 \\
\hline Preservation Units' data collected & 20 & 17 & 15 \\
\hline Preservation Units investigated & 133 & 141 & 138 \\
\hline Period (days) & 12 & 15 & 13 \\
\hline Ratio(\%) & 15.0 & 12.1 & 10.9 \\
\hline
\end{tabular}

Table 1. Data collection efficiency in the general plan of Chifeng cultural heritages conservation

\section{APPLICATION OF 3D LASER SCANNING IN GENERAL PLANS}

Although the time for data collection during the process of General Plans is limited, the planning team applies the $3 \mathrm{~d}$ laser scanning technology to collect the cloud point data of the Preservation Units which have higher value and need more accurate data. (Yuan, 2019)

\subsection{Technical process}

\subsubsection{Preparatory Work}

Faro has leading 3D measurement, imaging and implementation technologies in the industry. Therefore, the planning team chose

Faro Focus 3D X330 laser scanner for data collection projects in General Plans.

\subsubsection{Data Collection}

The main data collection process is as follows:
In the process of $3 \mathrm{D}$ laser scanning, the number and position of data collection stations should be reasonably planned according to the actual situation of Preservation Units, and the number of data collection stations should be reduced to improve the collection efficiency while ensuring the integrity of information collecting.

\section{Arrange Control Points}

When the high data accuracy is needed, or the surface and structure of Preservation Units are complex, the control points need be prepared in advance and reasonably arranged in the mapping area to facilitate data processing work afterwards and meet the accuracy requirements as well.

\section{Data Collection}

The data collection work can only be carried out after the preparation work is done. During the data collection, the site should be cleared to avoid the entry of irrelevant personnel and vehicles, and to prevent irrelevant data from blocking the Preservation Units.

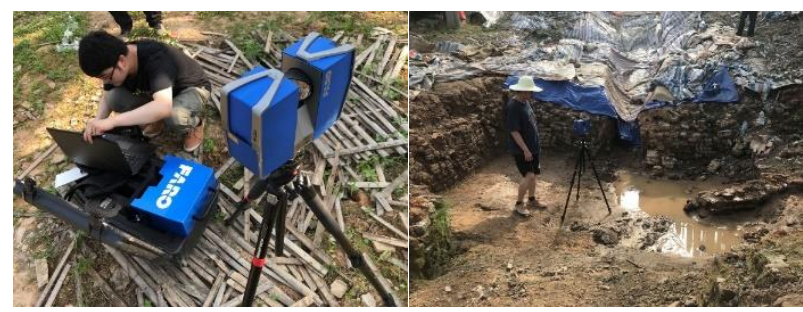

Figure 10. Data collection work on site

\subsubsection{Data Processing}

In the stage of internal data processing, we select Scene (FARO post-processing software) for data processing.

The major steps are as following:

\section{Data Import and Aligning}

After being imported into the workstation, the point cloud data obtained from multiple acquisition stations are aligned automatically. Manually adjustment of point cloud errors according to pre-arranged image control points should be carried out if necessary.

\section{3D Models Generating}

1. Station Position Arrangement 
After the selecting of processing range and deleting of irrelevant environmental data, the final point cloud model of the cultural heritage can be generated.

\subsection{Applications}

The 3D laser model has a high accuracy, and the preservation status of the Preservation Units can be completely recorded in the obtained data. After data processing, the digital archive can be generated to make orthophoto images of the cultural heritage, including plane, elevation and section, etc.

As the point cloud data collecting can be repeated, the multiperiod data comparison can be carried out to mark the areas where the point cloud has exceeded reasonable changes.

Based on the problems obtained in the multi-period point cloud comparison, the reason for the deformation of the Preservation Units, the occurrence range and influence degree of the manmade or natural risk and threat factors faced by the Preservation Units can be speculated. Finally, the corresponding protection measures and projects can be determined.

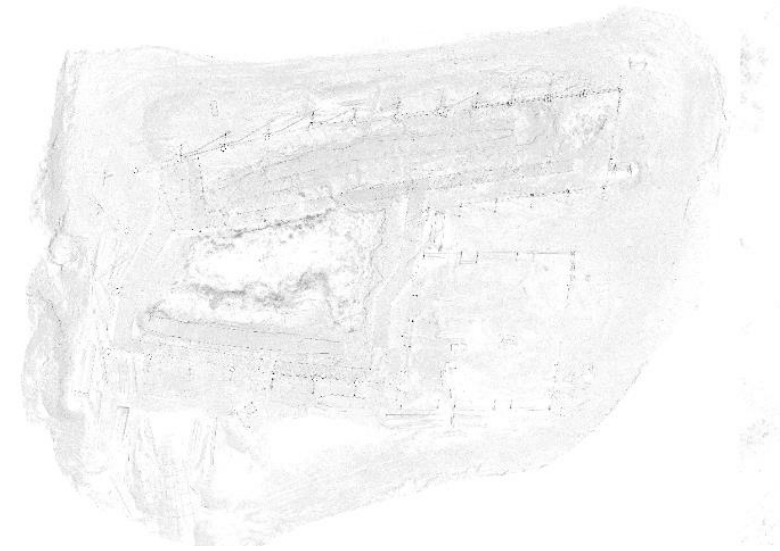

Figure 11. Dense point cloud data of a cultural heritage

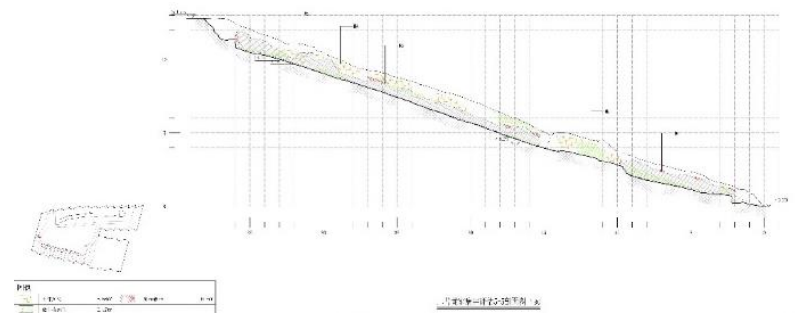

Figure 12. Condition assessment base on point cloud data by 3D laser scanning

\section{5 . TECHNOLOGY DEVELOPMENT PROSPECT}

In conclusion, the technologies of the geographic information system, the UVA photogrammetry and the $3 \mathrm{~d}$ laser scanning, which are being widely used in General Plans, have preliminary proves the feasibility of the space information technology application in the space analysis of cultural heritage data, efficient management, auxiliary planning and decision-making, efficient acquisition of space modeling data, dynamic monitoring, public participation and so on

The planning team will improve the cultural heritage information management system platform, increase the efficiency of data integration between the platform and the $3 \mathrm{~d}$ model data, and explore the possibility of expanding the functions of cultural heritage digital display (such as VR, AR) in the future work. 


\section{REFERENCES}

Institute of Architectural History, China Architecture Design Co.,Ltd. (IAH), 2004. General Plan for Cultural heritage Conservation and Tourism Development of Xinjiang Turfan. China Cultural Heritage, 2004(03), pp. 112-113.

Liu, T., 2017, Orthophoto processing software contrast between Inpho, PhotoScan and Pix4D. Technology and Industry Across the Straits, 2017(11), pp. 82-83.

Mao, F., Zhou, W., Huang, J., 2008, Research on the Application of Spatial Information Technology in the Conservation of Historical and Cultural Heritage. Journal of Urban and Regional Planning, 2008(1), pp. 87-99.

Shi, H., 2013. Reflections on Regional Cultural Heritage Conservation Planning. Architecture \& Culture, 2013(10), pp. 96-97.

Song, B., Zhao, Q.Y., 2019. Acquisition of High-Resolution Basic Terrain and Remote Sensing Image Data by Low-Altitude Photogrammetry of UAV, A Case Study of Pix4Dcapture, Pix4Dmapper and DJI Mavic Pro UAV. Geography Education, 2019(2), pp. 51-53.

Yu, Z.Z., Fan, H.R., Zhu, J.H., Luo, J.B., Guo, Q.Z., 2019. Research on UAV Single Lens Tilt Photogrammetry and 3DModeling Technology. Computer Engineering \& Software, 40(12), pp. 52-53.

Yuan, N., Gao, W., Hou, C.Y., 2019. Research and Progress of Terrestrial Laser Scanning Application in the Heritage Preservation. Journal of Tianjin Chengjian University, 25(1), pp. 65-69. 